\title{
PÃO COM ADIÇÃO DE INHAME
}

\section{BREAD WITH YAM ADDITION}

\author{
Maike Taís Maziero ${ }^{1}$, Cristina Maria Zanette ${ }^{2}$, Fabíula Melissa Stella ${ }^{3}$, Nina Waszczynskyj ${ }^{4}$ \\ ${ }^{1,2,3,4}$ Universidade Federal do Paraná - UFPR - Curitiba - Brasil maikemaziero@yahoo.com.br
}

\section{Resumo}

A adição de diferentes porcentagens de purê inhame em pão foi avaliada quando aos requisitos de volume, altura, rendimento e cor. O pão formulado com $10 \%$ de purê de inhame apresentou resultados de altura e volume mais próximos ao padrão, quando comparado com os pães adicionados de 20 e 30\% de inhame. A adição de purê de inhame não interferiu na cor do miolo do pão em nenhuma das formulações avaliadas, tendo também, pouco impacto na cor da crosta.

Palavras-chave: panificação, inhame, formulações.

\section{Introdução}

Usualmente os produtos de panificação são elaborados principalmente com farinha de trigo, pois este ingrediente proporciona melhores características de qualidade do produto final. O trigo é o único cereal que tem as proteínas gliadina e glutelina, que são as formadoras do glúten, em quantidade e qualidade adequadas para a produção de pães com características sensoriais desejadas (GALERA, 2006).

O Brasil consome aproximadamente 11 milhões de toneladas de trigo, das quais $50 \%$ são importados, principalmente da Argentina e do Canadá. Uma das alternativas para diminuir a importação de trigo e manter as características sensoriais do pão é a substituição parcial da farinha de trigo (JUNIOR et al., 2006). Várias são as possibilidades industriais para a produção de pães a partir do uso de farinhas mistas, inclusive com a mucilagem do inhame.

O inhame apresenta cerca de 28,1 - 29,5\% de matéria seca com 70,3 - 79,5\% de amido, 1,7 4,3\% de açúcares totais, 0,1 - 0,7\% de açúcares redutores, 0,6 - 2,9\% de fibra, 4,6 - 7,1 de proteína (LEONEL e CEREDA, 2002). Ao inhame são atribuídas algumas propriedades nutricionais e funcionais, pelo seu teor de minerais e vitaminas, assim como pelo seu conteúdo de fitoquímicos, como antocianinas, saponinas e polifenóis, além do teor de fibras (MIAMOTO, 2008). 
O inhame, por suas características nutricionais, tem possibilidades de uso humano sob diferentes formas de preparo, podendo substituir, total ou parcialmente, a batatinha, a mandioca, o milho, o trigo e outras espécies amídicas. A farinha de inhame pode ser adicionada à de trigo para a fabricação de pães ou pode ser utilizada em diversos pratos, doces ou salgados. Isso porque o consumo de pão em seus vários tipos constitui uma fonte alternativa de vitaminas, sais minerais e proteínas.

O objetivo deste trabalho foi avaliar diferentes níveis de substituição de inhame em formulações de pães e avaliar suas características físicas e sensoriais.

\section{Material e Métodos}

O inhame foi lavado em água corrente, descascado, cortado em cubos e cozido. Após o cozimento, a água foi retirada e o inhame levado ao multiprocessador Walita modelo Megamaster Plus para ser triturado até atingir consistência de purê.

No Quadro 1 encontram-se os ingredientes utilizados em cada experimento. Os ingredientes foram pesados em balança semi-analítica BEL classe III. Em seguida os ingredientes secos foram homogeneizados durante dois minutos na máquina de pão marca Britânia. Logo após foi adicionado o restante dos ingredientes e 90\% da água. Os 10\% restantes da água foram sendo adicionados aos poucos até que a massa atingisse a textura adequada. O tempo total de amassamento foi de 10 minutos.

Em seguida a massa foi retirada da amassadeira, acondicionada em bécker e levadas a câmara BOD Eletrolab modelo EL 202 (temperatura de $30^{\circ} \mathrm{C}$ ) durante 60 minutos. Após a $1^{\text {a }}$ fermentação, a massa foi sovada manualmente e colocada em forma untada com óleo. Procedeu-se a $2^{\mathrm{a}}$ fermentação por 70 minutos e as formas foram levadas ao Forno elétrico Vipinho, modelo 045002126, da marca Perfecta a $180-200^{\circ} \mathrm{C}$ durante 15 minutos.

\begin{tabular}{|c|c|c|c|c|}
\hline \multirow{2}{*}{ Ingredientes } & \multicolumn{4}{|c|}{ Formulações* } \\
\hline & Padrão & 10\% de inhame & $20 \%$ de inhame & $30 \%$ de inhame \\
\hline Farinha de trigo & 100,0 & 90,0 & 80,0 & 70 \\
\hline Água & 55,0 & 50,0 & 41,0 & 35,0 \\
\hline Purê de inhame & 0 & 10,0 & 20,0 & 30,0 \\
\hline Açúcar & 4,0 & 4,0 & 4,0 & 4,0 \\
\hline Óleo vegetal & 4,0 & 4,0 & 4,0 & 4,0 \\
\hline Sal & 2,3 & 2,3 & 2,3 & 2,3 \\
\hline Fermento & 1,5 & 1,5 & 1,5 & 1,5 \\
\hline
\end{tabular}


A umidade do purê de inhame e da farinha de trigo foi determinada por secagem sob infravermelho em equipamento Gehaka modelo BG-200 a temperatura de $130^{\circ} \mathrm{C}$ (CECCHI, 2003). O volume dos pães foi determinado pelo deslocamento de um volume conhecido de sementes de linhaça em um bécker e o volume específico foi obtido pela razão entre o volume $(\mathrm{mL})$ e a massa final dos pães (MOURA, 2008). A medida da altura foi realizada com régua milimetrada. O rendimento foi calculado pela razão entre a massa final dos pães após o resfriamento e a massa crua.

Determinou-se a cor da crosta e do miolo dos pães utilizando o colorímetro Mini Scan XE Plus (HunterLab) através do sistema $\mathrm{L}^{*}, \mathrm{a}^{*}, \mathrm{~b}^{*}$. A escala utilizada foi a Hunter $\mathrm{L}^{*}, \mathrm{a}^{*}$ e $\mathrm{b}^{*}$, que mede três dimensões da cor: $\mathrm{L}^{*}$ que representa o eixo da luminosidade, que vai de 0 (preto) a 100 (branco); a*, que representa o eixo vermelho-verde (valores positivos são vermelho, valores negativos verde e 0 é neutro) e b*, que representa o eixo amarelo-azul (valores positivos são amarelos, valores negativos azul e 0 é neutro) (HUNTERLAB, 2001). Os resultados foram avaliados estatisticamente pelo programa MSTAT-C, versão 2.10. A comparação das médias das diferentes formulações foi analisada segundo teste de Tukey $(\mathrm{p}<0,05)$.

\section{Resultados e Discussão}

A umidade encontrada para a amostra de farinha de trigo foi de 9,38\%, estando em acordo ao limite estabelecido pela RDC n 263 de 2005 que é de 15\%. Para o purê de inhame o valor da umidade encontrado foi de 72,32\%, este valor é semelhante ao estabelecido pela Tabela Brasileira de Composição de Alimentos (2008) que é de 73,3\%.

Os resultados da massa, volume, volume específico e rendimento dos pães elaborados estão apresentados no Quadro 2.

Quadro 2 - Resultados das medidas de massa, altura, volume e rendimento dos pães elaborados.

\begin{tabular}{|c|c|c|c|c|c|c|c|}
\hline Formulação & $\mathrm{m}_{\mathrm{o}}(\mathrm{g})$ & $\mathrm{m}_{\mathrm{i}}(\mathrm{g})$ & $\mathrm{m}_{\mathrm{f}}(\mathrm{g})$ & $\mathrm{h}(\mathrm{cm})$ & $\mathrm{V}\left(\mathrm{cm}^{3}\right)$ & $\mathrm{V}_{\mathrm{e}}\left(\mathrm{cm}^{3} / \mathrm{g}\right)$ & $\mathrm{R}(\%)$ \\
\hline Padrão & 328,1 & 310,3 & 305,4 & 10,5 & 750 & 2,45 & 93,08 \\
\hline $\begin{array}{c}10 \% \text { de } \\
\text { inhame }\end{array}$ & 312,1 & 291,3 & 286,7 & 10,0 & 650 & 2,26 & 91,86 \\
\hline $\begin{array}{c}20 \% \text { de } \\
\text { inhame }\end{array}$ & 294,7 & 277,2 & 271,4 & 8,8 & 550 & 2,02 & 92,09 \\
\hline $\begin{array}{c}30 \% \text { de } \\
\text { inhame }\end{array}$ & 277,1 & 260,1 & 255,1 & 8,5 & 500 & 1,96 & 92,06 \\
\hline
\end{tabular}

mo : Massa do pão cru

mi : Massa do pão após forneamento

$\mathrm{mf}$ : Massa do pão após resfriamento (30 min)

h: altura

$\mathrm{V}$ : volume

$\mathrm{R}$ : rendimento

Ve : Volume específico

O alto teor de água do purê de inhame (72,32\%) fez com que fosse necessária uma menor adição de água nos pães elaborados. A formulação elaborada com 30\% de inhame teve redução de 
36,4\% da quantidade de água adicionada e de 15,6\% da massa inicial em relação à formulação padrão. O rendimento dos pães adicionados de inhame foi ligeiramente inferior ao padrão.

A altura, o volume e o volume específico também foram variáveis que sofreram decréscimo com o aumento da adição de inhame (Figura 1). A formulação adicionada de $30 \%$ de inhame apresentou o menor volume específico de $1,96 \mathrm{~cm} 3 / \mathrm{g}$. Utilizando produtos sucedâneos como abóbora, batata doce e mandioca na produção de pães com 30\% de substituição da farinha de trigo CATANHO e MACIEL (2005) obtiveram valores de volume específico superiores ao do presente trabalho. O volume específico apresentou valores médios de: 2,07 cm³/g para o pão de abóbora; $2,94 \mathrm{~cm}^{3} / \mathrm{g}$ para o pão de batata doce e $3,13 \mathrm{~cm}^{3}$;/g para o pão de macaxeira.

Figura 1 - Pães com diferentes concentrações de Inhame

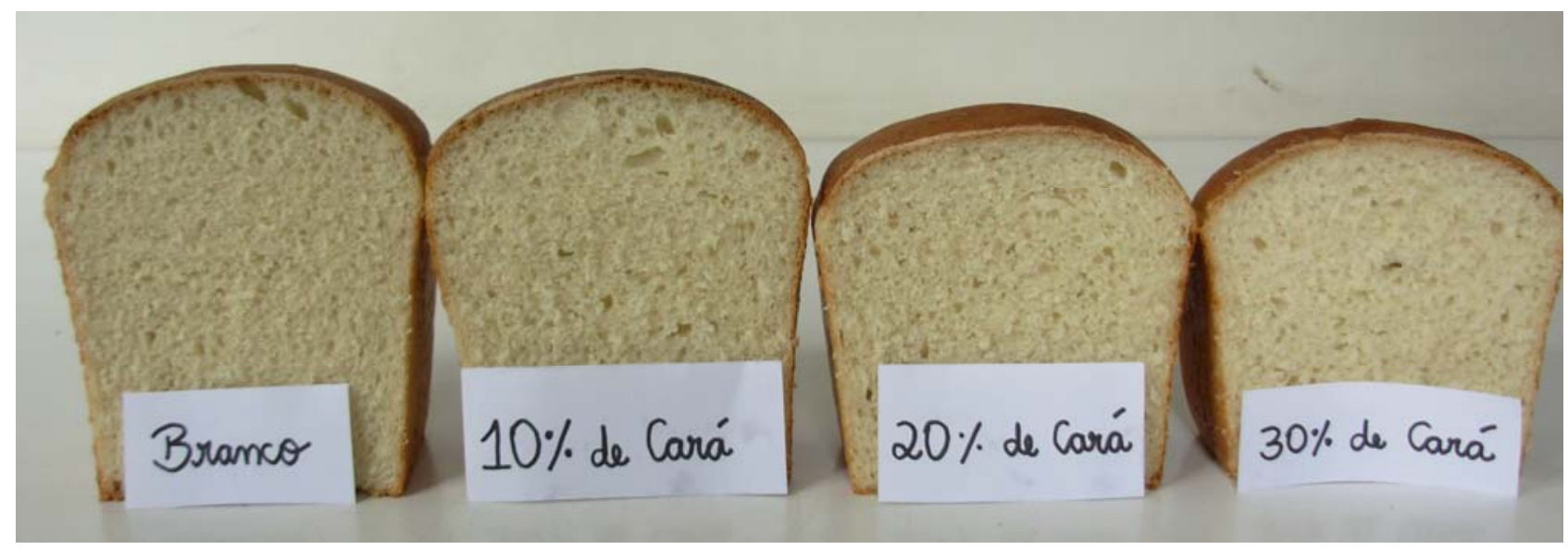

A Tabela 1 apresenta as médias dos resultados obtidos para os três parâmetros da cor.

Tabela 1 - Medida média da cor da casca e do miolo dos pães com diferentes concentrações de inhame

\begin{tabular}{ccccccc}
\hline Tratamento & \multicolumn{3}{c}{ Cor da casca } & \multicolumn{3}{c}{ Cor do miolo } \\
& $\mathbf{L}^{*}$ & $\mathbf{a}^{*}$ & $\mathbf{b}^{*}$ & $\mathbf{L}^{*}$ & $\mathbf{a}^{*}$ & $\mathbf{B}^{*}$ \\
Padrão & $47,21^{\mathrm{a}}$ & $15,85^{\mathrm{b}}$ & $29,03^{\mathrm{a}}$ & $78,62^{\mathrm{a}}$ & $1,455^{\mathrm{a}}$ & $22,78^{\mathrm{a}}$ \\
$10 \%$ de inhame & $40,57^{\mathrm{b}}$ & $14,05^{\mathrm{c}}$ & $22,35^{\mathrm{b}}$ & $78,57^{\mathrm{a}}$ & $1,10^{\mathrm{b}}$ & $22,09^{\mathrm{a}}$ \\
$20 \%$ de inhame & $43,65^{\mathrm{ab}}$ & $17,47^{\mathrm{a}}$ & $26,85^{\mathrm{a}}$ & $78,58^{\mathrm{a}}$ & $1,288^{\mathrm{ab}}$ & $22,45^{\mathrm{a}}$ \\
$30 \%$ de inhame & $44,63^{\mathrm{ab}}$ & $18,31^{\mathrm{a}}$ & $28,17^{\mathrm{a}}$ & $78,68^{\mathrm{a}}$ & $1,215^{\mathrm{ab}}$ & $22,58^{\mathrm{a}}$ \\
\hline
\end{tabular}

* Médias com a mesma letra na mesma coluna não diferem significativamente no intervalo de confiança de $95 \%$.

Para a cor da casca os valores de L* e mostram que os pães adicionados de inhame possuem luminosidade menor do que o padrão e os valores de a* revelam maior quantidade de tons de vermelho. Este fato pode ser explicado pela alta concentração de amido presente no inhame o que intensificaria a reação de Maillard.

Os valores de L* indicam alta luminosidade do miolo dos pães elaborados e a adição de inhame não afetou significativamente esta característica, o mesmo sendo observado para o 
parâmetro b*. Os baixos valores de a* indicam que os pães apresentam poucos tons de vermelho sendo que o tratamento padrão apresentou a maior média e diferiu estatisticamente do tratamento adicionado de $10 \%$ de inhame.

\title{
4. Conclusão
}

O pão formulado com 10\% de purê de inhame apresentou resultados de altura e volume mais próximos ao padrão, quando comparado com os pães adicionados de 20 e 30\% de inhame. A adição de purê de inhame não interferiu na cor do miolo do pão em nenhuma das formulações avaliadas, tendo também, pouco impacto na cor da crosta. Com relação às outras características sensoriais, uma análise subjetiva indicou que a adição de purê de inhame ao pão não causou impacto no sabor, odor e textura do mesmo. Portanto, a substituição da farinha de trigo por purê de inhame em até 10\% mostrou-se uma alternativa tecnológica viável para a produção de pães com boa qualidade sensorial.

\begin{abstract}
The addition of several percentages of yam pasta in bread formulation was evaluated by the parameters of volume, size, yield and color. The bread formulated with $10 \%$ of yam pasta had results of size and volume closer to the standard comparing to the breads with 20 and $30 \%$ of addition. The yam pasta addition didn't change the color of the bread heart for all evaluated formulations and had fill impact on the edge color.
\end{abstract}

Key-words: yam pasta, breads formulation, bakery.

\section{Referências}

CATANHO, P.T. ; MACIEL, M. I. Avaliação dos parâmetros físicos e sensoriais de pães de forma, com 30\% de produtos sucedâneos. Revista Higiene Alimentar, v.19, ed. 137, 2005.

CECCHI, H.M. Fundamentos teóricos e práticos em análise de alimentos, $2^{\circ}$ Edição. Editora Unicamp. 2003

GALERA, J. Substituição parcial da farinha de trigo por farinha de arroz (Oryza sativa L.) na produção de "sonho” estudo modelo. São Paulo, 2006. Dissertação de mestrado - Universidade de São Paulo.

JUNIOR, M.S.S.; OLIVEIRA, W.M.; CALIARI, M.; VERA, R. Otimização da formulação de pães de forma preparados com diferentes proporções de farinha de trigo, fécula de mandioca e okara. B. CEPPA, v. 24, n. 1, p. 221248, 2006.

HUNTERLAB- Hunter Associates Laboratory, Inc. 2001 The Basics of color perception and measurement. Disponível em< http://www.hunterlab.com/pdf/color.pdf> . Acesso em 16 nov. 2008.

LEONEL, M.; CEREDA, M.P. Caracterização físico-química de algumas tuberosas amiláceas. Cienc. Tecnol. Aliment. v.22, n.1, p.65-69, 2002.

MIAMOTO, J.B.M. Obtenção e caracterização de biscoito tipo cookie elaborado com farinha de inhame (Colocasia esculenta L.) Dissertação de mestrado. UFLA, 2008.

MOURA, N.C. Característica físico-químicas , nutricionais e sensoriais de pão de forma com adição de grãos de linhaça (Linum usitatissimum). Piracicaba, 2008. Dissertação de Mestrado - Universidade de São Paulo. 
Tabela Brasileira de Composição de Alimentos. Disponível em $<$ http://www.fcf.usp.br/tabela/resultado.asp?IDLetter=B\&IDNumber=139> Acesso em 12 nov. de 2008.

Nome: Maike Taís Maziero

Filiação institucional: Universidade Federal do Paraná

Função ou cargo ocupado: Doutoranda em Tecnologia de Alimentos

Endereço: Centro Politécnico. Caixa Postal 19011

81531-990 Curitiba - PR.

Telefone para contato: (41) 3361-3232.

e-mail: maikemaziero@yahoo.com.br

Nome: Cristina Maria Zanette

Filiação institucional: Universidade Federal do Paraná

Função ou cargo ocupado: Mestranda em Tecnologia de Alimentos

Endereço: Centro Politécnico. Caixa Postal 19011

81531-990 Curitiba - PR.

Fone: (41) 3361-3232.

e-mail: tininhazanette@yahoo.com.br

Fabíula Melissa Stella

Universidade Federal do Paraná

Mestranda em Tecnologia de Alimentos

Centro Politécnico. Caixa Postal 19011

81531-990 Curitiba - PR.

Telefone para contato: (41) 3361-3232.

e-mail: fmsetlla@ufpr.br

Nina Waszczynskyj

Filiação institucional: Universidade Federal do Paraná

Função ou cargo ocupado: Doutora em Ciências (Bioquímica) Professora Sênior

Endereço: Centro Politécnico. Caixa Postal 19011

81531-990 Curitiba - PR.

Telefone para contato: (41) 3361-3232.

e-mail: ninawas@ufpr.br 